This work is licensed under a Creative Commons Attribution License (CC BY 4.0).

\title{
Litinium gludi sp. nov. (Nematoda, Oxystominidae) from Kermadec Trench, Southwest Pacific Ocean
}

\author{
Daniel LEDUC ${ }^{1, *} \&$ Zeng Qi $\mathrm{ZHAO}^{2}$ \\ ${ }^{1}$ National Institute of Water and Atmospheric Research (NIWA) Ltd, Wellington, New Zealand. \\ ${ }^{2}$ Landcare Research, Private Bag 92170, Auckland Mail Centre, Auckland 1142, New Zealand. \\ *Corresponding author: Daniel.Leduc@niwa.co.nz \\ 2Email: Zhaoz@1andcareresearch.co.nz \\ ${ }^{1}$ urn:1sid:zoobank.org:author:9393949F-3426-4EE2-8BDE-DEFFACE3D9BC \\ ${ }^{2}$ urn:1sid:zoobank.org:author:F5BEE9FD-801A-49C6-9585-C765EE77A123
}

\begin{abstract}
Recent work on the taxonomy of nematodes in Southwest Pacific Ocean trenches has led to the discovery of taxa which so far appear to be restricted to the oceans' deepest environments. Here, Litinium gludi sp. nov. is described based on specimens obtained from a deep basin within the Kermadec Trench at $9540 \mathrm{~m}$ water depth. The new species differs from other species of the genus in having a conico-cylindrical tail, papillose labial sensilla, and heart- or leaf-shaped amphideal fovea. Both SSU and LSU phylogenetic analyses provide strong support for the placement of the new species within a clade containing both Thalassoalaimus and Litinum, and within Oxystomininae, which is consistent with the structure of the female reproductive system with only one posterior ovary in this subfamily. Our molecular analyses also indicate that the new species is most closely related to Thalassoalaimus despite lacking a caudal capsule, the main trait characterizing the latter genus, and despite being most morphologically similar to Litinium, particularly in the unusual shape of the amphideal fovea. However, given the changing definitions of the closely-related genera Thalassoalaimus and Litinium in recent years, available GenBank sequences may have been misidentified, which makes the interpretation of molecular phylogenetic analyses problematic. Given the current morphological definitions of Litinium and Thalassoalaimus, we choose to place the new species within Litinium, despite the apparently contradictory findings of molecular phylogenetic analyses. The placement of Cricohalalaimus in a clade with Thalassoalaimus and Litinium in both SSU and LSU analyses indicates that this genus should be placed within the Oxystomininae and not the Halalaiminae as in the current classification. This new proposed grouping is consistent with variation in the structure of the female reproductive system, a feature which appears more taxonomically informative than amphid shape for subfamily-level classification.
\end{abstract}

Keywords. Hadal, Oxystomininae, Cricohalalaimus, small subunit 18S rDNA, D2-D3 region of large subunit 28S rDNA.

Leduc D. \& Zhao Z.Q. 2021. Litinium gludi sp. nov. (Nematoda, Oxystominidae) from Kermadec Trench, Southwest Pacific Ocean. European Journal of Taxonomy 748: 138-154. https://doi.org/10.5852/ejt.2021.748.1347 


\section{Introduction}

The Oxystominidae Chitwood, 1935 (order Enoplida Filipjev, 1929) is among the most common nematode families in deep-sea environments (Gambi et al. 2003; Bik et al. 2010a; Miljutin et al. 2010). This largely marine group is characterized by a thin elongated body, the outer labial and cephalic sensilla in separate circles, and the buccal cavity without teeth (Lorenzen 1981). The family includes three subfamilies: the Oxystomininae Chitwood, 1935, Halalaiminae De Coninck, 1965 and Paroxystomininae De Coninck, 1965, which are differentiated based on the amphid shape, the structure of the female reproductive system and the presence/structure of the precloacal supplements. The Oxystomininae comprises five genera, all of which except Oxystomina Chitwood, 1935 are exclusively marine; the presence of only the posterior ovary is considered a holapomorphy establishing the holophyly of the Oxystomininae (Lorenzen 1981). The Halalaiminae originally comprised a single genus, Halalaimus de Man, 1888, which is characterized by an elongated longitudinal amphideal aperture, an holapomorphic trait establishing the holophyly of the subfamily. The genus Cricohalalaimus Bussau, 1993 was later included in the subfamily by Smol et al. (2014) based on the similar structure of the amphideal aperture; this genus, however, is also characterized by the presence of a single posterior ovary in females, a feature of the Oxystomininae. There is no holapomorphy for the Paroxystominae, which comprises Paroxystomina Micoletzky, 1924 and Maldivea Gerlach, 1962 (Lorenzen 1981). Phylogenetic analyses based on SSU sequences do not provide support for the monophyly of the Oxystominae or Halalaminae (Bik et al. 2010a), and no molecular sequences are yet available for the Paroxystomininae.

The majority of marine free-living nematode genera have wide water depth distributions spanning both coastal and deep-sea environments (> $200 \mathrm{~m}$ water depth), but some are mostly found in the deep sea (e.g., Acantholaimus Allgén, 1933, Metasphaerolaimus Gourbault \& Boucher, 1981), while others are found exclusively in continental slope and/or deeper environments (e.g., Bathyeurystomina Lambshead \& Platt, 1979, Thelonema Bussau, 1993, Manganonema Bussau, 1993). Phylogenetic analyses based on SSU data suggest repeated and recent interchanges between the deep sea and shallow water environments, with habitat transitions thought to be frequent for free-living nematodes (Bik et al. 2010b). In Halalaimus and Oxystomina, shallow water species appear to have evolved from deep water ancestors (Bik et al. 2010b); however, within the Oxystominidae, Cricohalalaimus Bussau, 1993 is the only genus with a distribution strictly restricted to the deep sea.

Limited core sampling has been conducted in hadal trenches to date ( $>6000 \mathrm{~m}$ water depth), resulting in scant knowledge of nematode systematics in the deepest parts of the world's oceans. Taxonomic work on Tonga and Kermadec trench material has led to the discovery of new species and genera which so far appear to be restricted to hadal environments (Leduc 2015, 2016). More recently, sampling within the deep Kermadec Trench axis provided core samples from the trench's deepest basins, and the examination of specimens from a site located at $9540 \mathrm{~m}$ depth led to the discovery of a species of nematode, Litinium gludi sp. nov., which is described here. Phylogenetic relationships of this new species within the Oxystominidae are investigated using SSU and D2-D3 of LSU rDNA sequences.

\section{Material and methods}

\section{Study area and sampling}

The Kermadec Trench extends from approximately from 26 to $36^{\circ} \mathrm{S}$ near the northeastern tip of New Zealand's North Island, Southwest Pacific Ocean. Sediment samples were obtained from the deep axis of Kermadec Trench at $9540 \mathrm{~m}$ depth during RV Tangaroa cruise TAN1711 in December 2017. Sediments were obtained using a USNEL-type box corer (dimensions: $0.5 \times 0.5 \times 0.5 \mathrm{~m}, 0.125 \mathrm{~m}^{3}$ capacity). Subsamples were obtained using a cut-off syringe with $29 \mathrm{~mm}$ internal diameter to a depth of $10 \mathrm{~cm}$. Subsamples for morphological analyses were sliced into $1 \mathrm{~cm}$ layers and fixed in $10 \%$ buffered formalin. Nematodes were extracted from the remaining sediments by Ludox flotation and transferred to pure 
glycerol (Somerfield \& Warwick 1996). Species descriptions were made from glycerol mounts using differential interference contrast microscopy and drawings were made with the aid of a camera lucida. Measurements were obtained using an Olympus BX53 compound microscope with cellSens Standard software for digital image analysis.

Subsamples for molecular analyses were obtained as described above but the samples were frozen at $-80^{\circ} \mathrm{C}$ instead of being fixed in formalin. In the laboratory, frozen sediment samples were thawed overnight, then sieved trough a $20 \mu \mathrm{m}$ mesh to retain nematodes. Nematodes were extracted using the Ludox flotation method (Somerfield \& Warwick 1996) and sorted under a dissecting microscope. One juvenile Litinium gludi sp. nov. specimen was isolated and transferred to a temporary slide to confirm its identity. This specimen was identified based on the characteristic shape of the cephalic region, cephalic sensilla, amphids, and tail.

All measurements are in $\mu \mathrm{m}$ (unless otherwise stated), and all curved structures are measured along the arc. Type specimens are held in the NIWA Invertebrate Collection, Wellington, New Zealand.

\section{List of abbreviations}

$\mathrm{a}=$ body length/maximum body diameter

$\mathrm{b}=$ body length/pharynx length

$\mathrm{c}=$ body length/tail length

$\mathrm{c}^{\prime}=$ tail length/anal or cloacal body diameter

cbd $=$ corresponding body diameter

$\mathrm{L}=$ total body length; $\mathrm{n}$, number of specimens

$\mathrm{V}=$ vulva distance from anterior end of body

$\% \mathrm{~V}=\mathrm{V} /$ total body length $\times 100$

\section{DNA extraction, PCR and sequencing}

Following observation under a compound microscope, the specimen was transferred to lysis buffer and kept frozen at $-80^{\circ} \mathrm{C}$ prior to molecular analyses. DNA was extracted by the method of Zheng et al. (2002) with minor modifications (i.e., the nematode was not cut prior to being transferred to the lysis buffer solution). The DNA extract was stored at $-20^{\circ} \mathrm{C}$ until used as PCR template.

Primers for LSU amplification were forward primer D2A (5' ACAAGTACCGTGAGGGAAAGT 3') and reverse primer D3B (5' TGCGAAGGAACCAGCTACTA 3') (Nunn 1992). Primers for the rDNA small subunit (SSU) were the forward primer 1096F, 5'-GGTAATTCTGGAGCTAATAC-3' and reverse primer 1912R, 5'-TTTACGGTCAGAACTAGGG-3' (first fragment), and the forward primer 1813F, 5'-CTGCGTGAGAGGTGAAAT-3' and reverse 2646R, 5'-GCTACCTTGTTACGACTTTT-3' (second fragment) (Holterman et al. 2006). For both SSU and LSU, the $20 \mu 1$ PCR contained $10 \mu 1$ REDExtractN-Amp PCR ReadyMix (Sigma-Aldrich, USA), $1 \mu \mathrm{l}(5 \mu \mathrm{M})$ each of forward and reverse primers, and $2 \mu \mathrm{l}$ of DNA template. The thermal cycling program was as follows: denaturation at $95^{\circ} \mathrm{C}$ for $3 \mathrm{~min}$, followed by 40 cycles of denaturation at $94^{\circ} \mathrm{C}$ for $15 \mathrm{~s}$, annealing at $55^{\circ} \mathrm{C}$ for $30 \mathrm{~s}$, and extension at $72^{\circ} \mathrm{C}$ for $30 \mathrm{~s}$. A final extension was performed at $72^{\circ} \mathrm{C}$ for $7 \mathrm{~min}$. The amplicons were electrophoresed on $1 \%$ TAE-agarose gel stained with $\mathrm{SYBR}^{\circledR}$ Safe, observed under UV illumination using the Gel-Doc system (BioRad, Hercules, CA, USA), and images processed using the Image Lab ver. 5.1 analysis software (BioRad). The PCR products were sequenced bi-directionally using the amplification primers by EcoGene (Auckland, New Zealand). Sequences were obtained with a 3500xL Genetic Analyzer (Applied Biosystems, USA) and assembled and edited with Sequencher ver. 4.10.1 (Gene Codes Corp.). 


\title{
Sequence alignment and phylogenetic inference
}

The ribosomal DNA SSU and LSU D2-D3 sequences were deposited in GenBank under accession numbers MW209715 and MW209714, respectively. The placement of the new SSU and D2-D3 of LSU sequences was investigated through a phylogenetic analysis of the representative genera of the Oxystominidae, as well as the Rhaptothyreidae Hope \& Murphy, 1969 and Oncholaimoidea Filipjev, 1916, which have been shown to be closely related (Bik et al. 2010a; Leduc et al. 2018), and rooted using Ironidae de Man, 1876 sequences (all SSU sequences > $1300 \mathrm{bp}$ except four ca $800 \mathrm{bp}$, and D2-D3 of LSU sequences $>600 \mathrm{bp}$ ).

DNA sequences were aligned using MUSCLE (Edgar 2004a, 2004b) with default parameters. Phylogenies were built in Geneious ver. 10.2.6 (http://www.geneious.com, Kearse et al. 2012). MrModelTest ver. 2.3 (Nylander 2004) in conjunction with PAUP* ver. 4.0b10 (Swofford 2002) were used to select the best model using the Akaike Information Criterion. The substitution model [GTR (general time-reversible) $+\mathrm{I}$ (proportion of invariable sites) $+\mathrm{G}$ (gamma distribution)] was selected as the best-fit model for SSU alignments (1522 bp) and LSU alignments (722 bp), respectively. The trees were run with chain length of 1100000 , and burn-in length of 100000 . The perimeter files from multiple runs were inspected for chain convergence in Tracer ver. 1.5 (Rambaut \& Drummond 2007), and the trees were edited in FigTree ver. 1.4.2 (http://tree.bio.ed.ac.uk/software/figtree) and PowerPoint. These analyses were also conducted with PhyML ver. 3.0 using the default settings in Geneious ver. 10.2.6. The substitution model GTR, the NNI (default, fast) topology search and 1000 bootstrap replicates (Guindon et al. 2010) were selected for building the tree.

\section{Results}

\section{Systematics}

\author{
Phylum Nematoda Diesing, 1861 \\ Order Enoplida Filipjev, 1929 \\ Suborder Ironina Siddiqi, 1983 \\ Superfamily Ironoidea de Man, 1876
}

Family Oxystominidae Chitwood, 1935

Diagnosis (emended from Smol et al. 2014)

Body elongated and very thin at anterior end. Anterior sensilla in three separate circles, second and third circles clearly separated; inner labial sensilla papilliform or setiform, outer labial sensilla usually setiform (except in some species of Litinium), cephalic sensilla setiform. Buccal cavity narrow, tubular or funnelshaped and without teeth. Sexual dimorphism in amphid shape sometimes present. Only orthometanemes with very short caudal filaments present. Pharynx inserts into body cuticle in region of buccal cavity; however, cephalic capsule not well developed. Posterior section of pharynx with undulating outline. Females didelphic-amphidelphic with antidromously reflexed ovaries or monodelphic-opisthodelphic. Males diorchic with opposed testes or only one anterior testis. Position of caudal glands variable.

Subfamily Oxystomininae Chitwood, 1935

Diagnosis (modified from Smol et al. 2014)

Only dorsolateral orthometanemes, ventral gland when present confined within pharyngeal region. Amphideal fovea and aperture variable but amphideal aperture never elongated, precloacal supplements (when present) papilliform, in single ventral row. Females monodelphic-opisthodelphic. 


\section{Type genus}

Oxystomina Filipjev, 1918

\section{Other valid genera}

Litinium Cobb, 1920

Nemanema Cobb, 1920

Thalassoalaimus de Man, 1893

Wieseria Gerlach, 1956

\section{Litinium Cobb, 1920}

Diagnosis (modified from Tchesunov et al. 2014)

Circles of six inner and six outer labial papillae $(<2 \mu \mathrm{m})$ or setae $(\geq 2 \mu \mathrm{m})$ situated close together on anterior end, subapically, with circle of four cephalic papillae or setae posterior to circles of inner and outer labial sensilla. Amphideal fovea situated between circles of outer labial and cephalic sensilla. Amphideal fovea varies in shape between species and may differ in males and females of same species: may be ovoid with anterior round aperture, horseshoe-like or crescent contoured or more complex. Only one posterior antidromously reflexed ovary present; vulva shifted anteriorly. Tail never clavate, more or less short, cylindrical with rounded tip, occasionally conical or conico-cylindrical with pointed tip; terminal caudal capsule (thick cuticular lining at tip of tail) absent or weakly developed.

\section{Remarks}

The amphid of some species of Litinium Cobb, 1920 is described as being "horseshoe-shaped". In the new species, our observations indicate that it is the superimposition of the amphideal aperture contour over the larger amphideal fovea contours that creates the appearance of a horseshoe-shaped structure. Whether this is also the case in other species of Litinium remains to be clarified.

There has been some confusion regarding the definitions of Litinium and Thalassoalaimus. The diagnoses provided by Smol et al. (2014) indicate that the two genera differ in the shape of the amphids (pocketshaped amphideal fovea and slit-like aperture in Thalassoalaimus vs horseshoe- or heart-shaped fovea and round aperture in Litinium) and presence (Thalassoalaimus) or absence (Litinium) of a caudal capsule. However, we note that the pocket-shaped amphideal fovea and slit-like aperture in Litinium subterraneum Tchesunov, Mokievsky \& Nguyen Vu Thanh, 2010 is identical to that of Thalassoalaimus. On the other hand, Litinium profundorum Tchesunov, Nguyen Vu Thanh \& Nguyen Dinh Tu, 2014 has a weak thickening of the inner cuticle layer of the tail tip resembling a caudal capsule but is characterised by a horseshoe-shaped amphideal fovea typical of the genus Litinium. Most recently, Martelli et al. (2017) used the presence or absence of a caudal capsule as the sole distinguishing feature between the two genera, resulting in the transfer of several species of Thalassoalaimus to Litinium. Some of the newly transferred species, namely L. aceratus (Vitiello, 1970) Martelli, Lo Russo, Villares \& Pastor de Ward, 2017 and L. longicaudatus (Vitiello, 1970) Martelli, Lo Russo, Villares \& Pastor de Ward, 2017, as well as $L$. gludi sp. nov., are characterised by conico-cylindrical tails, which require the genus diagnosis of Tchesunov et al. (2014) to be emended. In addition, L. longicaudatus, L. qangi Tchesunov, Nguyen Vu Thanh \& Nguyen Dinh Tu, 2014, L. curticauda Tchesunov, Nguyen Vu Thanh \& Nguyen Dinh Tu, 2014 and $L$. gludi sp. nov. are characterised by papillose to short setose labial sensilla $(0.5-2.5 \mu \mathrm{m}$ long), unlike all other species of the genus which have exclusively setose $(\geq 2 \mu \mathrm{m})$ labial sensilla. 


\section{List of valid species}

L. abyssorum Tchesunov, Nguyen Vu Thanh \& Nguyen Dinh Tu, 2014

L. aceratus (Vitiello, 1970) Martelli, Lo Russo, Villares \& Pastor de Ward 2017

L. aequale Cobb, 1920

L. australis Martelli, Lo Russo, Villares \& Pastor de Ward, 2017

L. bananum Gerlach, 1956

L. curticauda Tchesunov, Nguyen Vu Thanh \& Nguyen Dinh Tu, 2014

L. dispariseta Yu \& Xu, 2018

L. egregius (Steiner, 1916) Martelli, Lo Russo, Villares \& Pastor de Ward 2017

L. gludi sp. nov.

L. longicaudatus (Vitiello, 1970) Martelli, Lo Russo, Villares \& Pastor de Ward 2017

L. obtusilobus Bussau, 1993

L. paramontemari (Vitiello, 1970) Martelli, Lo Russo, Villares \& Pastor de Ward 2017

L. parmatum Wieser, 1954

L. pirum (Lorenzen, 1969) Martelli, Lo Russo, Villares \& Pastor de Ward 2017

L. profundorum Tchesunov, Nguyen Vu Thanh \& Nguyen Dinh Tu, 2014

L. quamgi Tchesunov, Nguyen Vu Thanh \& Nguyen Dinh Tu, 2014

L. setosus (Timm, 1967) Martelli, Lo Russo, Villares \& Pastor de Ward 2017

L. subterraneum Tchesunov, Mokievsky \& Nguyen Vu Thanh, 2010

L. volutum Gerlach, 1962

Litinium gludi sp. nov.

urn:lsid:zoobank.org:act:FA79DFEF-A389-48AA-AF75-03984D69F202

Figs 1-4, Table 1

\section{Diagnosis}

Litinium gludi sp. nov. is characterised by a slender body $(\mathrm{a}=58-63)$, a body length of $895-1066 \mu \mathrm{m}$, papilliform labial sensilla, short cephalic sensilla $1.5-2.0 \mu \mathrm{m}$ or $\sim 0.2$ cbd long, a large heart- or leafshaped amphideal fovea $67-88 \%$ cbd wide, a smaller amphideal aperture with two central longitudinal ridges, males with dimorphic sperm, spicules 1.1-1.4 times cloacal body diameter, a short and simple gubernaculum, and two precloacal setae.

\section{Differential diagnosis}

The new species resembles L. aceratus and L. longicaudatus, the only other species of the genus with conico-cylindrical tails, and is particularly similar to L. longicaudataus in having papillose $(<2 \mu \mathrm{m})$ labial sensilla. Litinium gludi sp. nov. can be differentiated from L. longicaudatus by the shorter body (895-1066 vs 2180-2196 $\mu \mathrm{m}$ in L. longicaudatus), lower 'a' ratio (58-63 vs 75-86), and heart- or leafshaped amphideal fovea (vs pocket-shaped).

\section{Etymology}

The species is named after Professor Ronnie Glud, leader of the HADES-ERC trench project and covoyage leader.

\section{Material examined}

Holotype

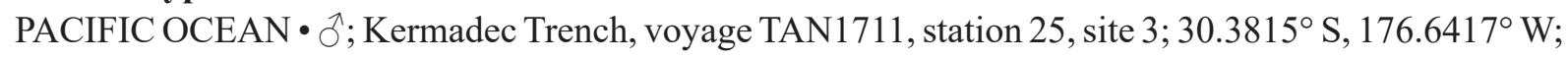
$9540 \mathrm{~m}$ water depth, 0-2 cm sediment depth; 3 Dec. 2017; NIWA 139257. 
Table 1. Morphometrics ( $\mu \mathrm{m})$ of Litinium gludi sp. nov.

\begin{tabular}{|c|c|c|c|c|}
\hline \multirow[b]{3}{*}{ Specimen } & \multicolumn{3}{|c|}{ Males } & \multirow{3}{*}{$\begin{array}{c}\text { Female paratype } \\
\text { F1 }\end{array}$} \\
\hline & \multirow{2}{*}{$\begin{array}{c}\text { Holotype } \\
\text { M1 }\end{array}$} & \multicolumn{2}{|c|}{ Paratypes } & \\
\hline & & M2 & M3 & \\
\hline $\mathrm{L}$ & 1027 & 895 & 1066 & 930 \\
\hline $\mathrm{a}$ & 60 & 60 & 63 & 58 \\
\hline $\mathrm{b}$ & 5 & 4 & 5 & 5 \\
\hline $\mathrm{c}$ & 11 & 10 & 11 & 10 \\
\hline$c^{\prime}$ & 7.3 & 7.8 & 6.9 & 9.3 \\
\hline Body diam. at outer labial sensilla & 6 & 6 & 6 & 6 \\
\hline Body diam. at cephalic setae & 9 & 9 & 9 & 9 \\
\hline Body diam. at amphids & 9 & 8 & 9 & 9 \\
\hline Length of cephalic sensilla & $1.6-1.9$ & $1.6-1.8$ & $1.5-2.0$ & 1.8 \\
\hline Amphideal fovea height & 10 & 8 & 9 & 9 \\
\hline Amphideal fovea width & 7 & 7 & 6 & 7 \\
\hline Amphideal fovea width/cbd (\%) & 78 & 88 & 67 & 78 \\
\hline Amphideal fovea from anterior end & 4 & 5 & 4 & 5 \\
\hline Amphideal aperture height & 7 & 6 & 6 & 6 \\
\hline Amphideal aperture width & 3 & 3 & 3 & 3 \\
\hline Nerve ring from anterior end & 85 & 77 & 87 & 83 \\
\hline Nerve ring cbd & 17 & 15 & 17 & 16 \\
\hline Pharynx length & 208 & 200 & 211 & 195 \\
\hline Pharyngeal diam. at base & 12 & 9 & 11 & 10 \\
\hline Pharynx cbd at base & 15 & 12 & 15 & 13 \\
\hline Max. body diam. & 17 & 15 & 17 & 16 \\
\hline Spicule length & 18 & 15 & 16 & - \\
\hline Gubernacular apophyses length & 3 & 2 & 3 & - \\
\hline Cloacal/anal body diam. & 13 & 12 & 14 & 10 \\
\hline Tail length & 95 & 93 & 96 & 93 \\
\hline $\mathrm{V}$ & - & - & - & 329 \\
\hline$\% \mathrm{~V}$ & - & - & - & 35 \\
\hline Vulval body diam. & - & - & - & 14 \\
\hline
\end{tabular}

\section{Paratypes}

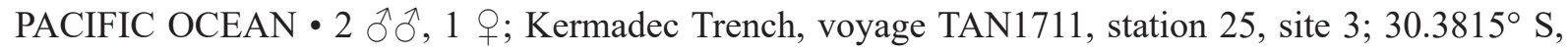
$176.6417^{\circ} \mathrm{W}$; $9540 \mathrm{~m}$ water depth, 0-2 cm sediment depth; 3 Dec. 2017; NIWA 139258.

\section{Description}

\section{Males}

Body slender, cylindrical, widest at level of nerve ring, tapering slightly towards anterior extremity. Cuticle smooth, without ornamentation; somatic setae absent, except for sparse sublateral setae on tail. Cephalic region demarcated by slight constriction near posterior edge of amphideal fovea. Inner labial sensilla not observed; six outer labial papillae, $\sim 0.5 \mu \mathrm{m}$ long, located slightly anterior to amphideal fovea and four short cephalic sensilla, $1.5-2.0 \mu \mathrm{m}$ or $\sim 0.2 \mathrm{cbd}$ long, situated far posteriorly at level of posterior edge of amphideal fovea. Amphideal fovea large, heart- or drop-shaped, with lightly cuticularized outline; amphideal aperture smaller, oval- or drop shaped, with two lightly cuticularized longitudinal central ridges spanning long axis of amphideal fovea. Buccal cavity narrow, cylindrical, with cuticularized portion 3-5 $\mu \mathrm{m}$ deep. Pharynx muscular, cylindrical, surrounding posterior portion 
of buccal cavity, widening towards posterior extremity but not forming true bulb. Nerve ring located slightly anterior to middle of pharynx. Secretory-excretory system not observed. Cardia 2-4 $\mu \mathrm{m}$ long, partially embedded in intestine.

Reproductive system with two opposed and outstretched testes; anterior testis located to the left or right of intestine, posterior testis located on opposite side or on same side. Mature sperm in anterior testis large, elongated, 19-21 ×2-3 $\mu \mathrm{m}$; mature sperm in posterior testis smaller, globular, $1.5 \times 1.5-2.0 \mu \mathrm{m}$. Spicules short, 1.1-1.4 times cloacal body diameter, curved distally, with ventrally bent capitulum. Gubernaculum small, simple, block-shaped, without lateral pieces, with poorly developed apophyses. Two precloacal papillae, 1.3-1.4 $\mu \mathrm{m}$ long; posterior-most papilla located 11-14 $\mu \mathrm{m}$ anterior to cloaca,
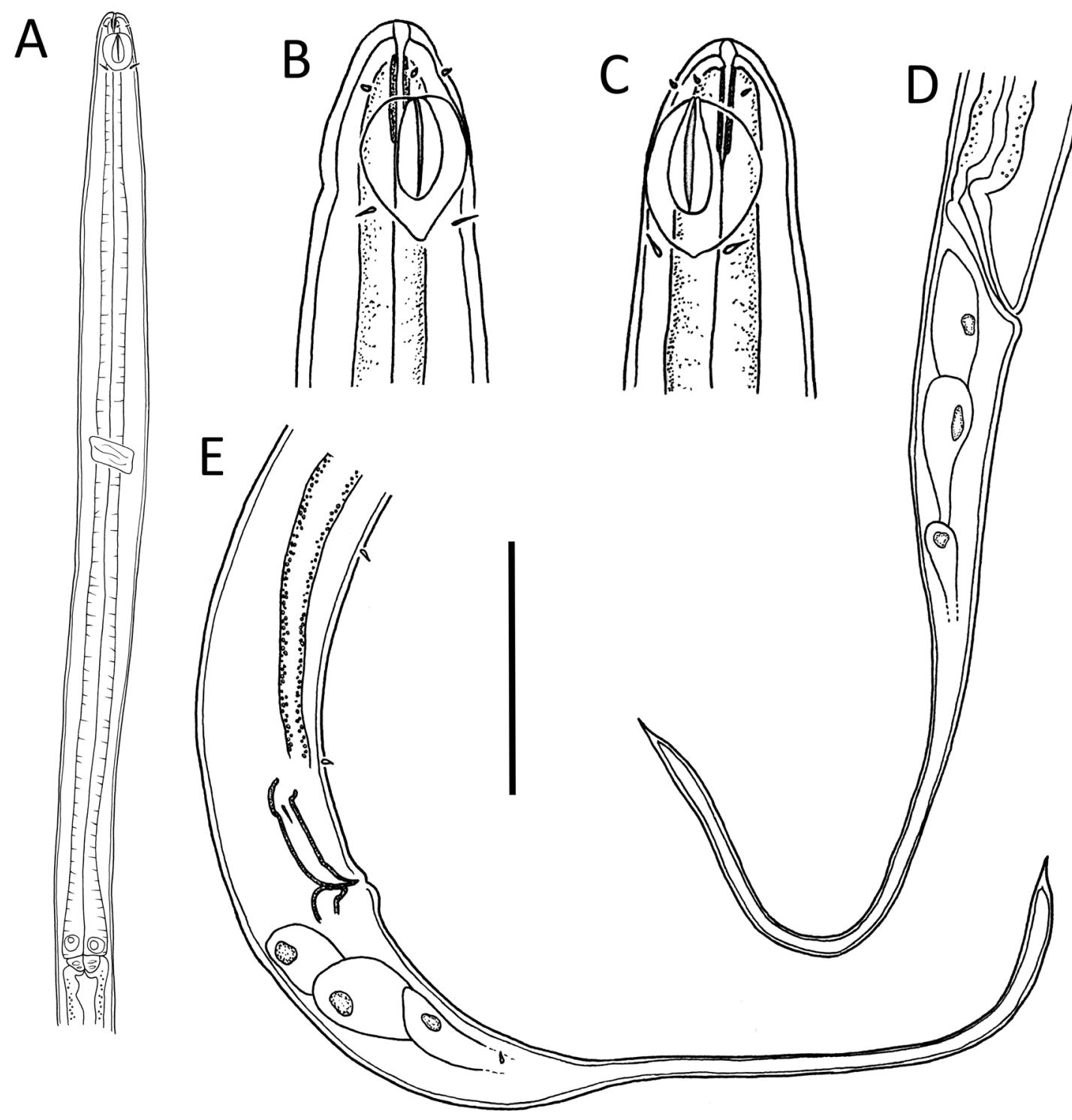

Fig. 1. Litinium gludi sp. nov. A. Anterior body region of the male holotype (NIWA 139257). B. Cephalic region of the female paratype (NIWA 139258). C. Cephalic region of the male paratype (NIWA 139258). D. Posterior body region of the female paratype (NIWA 139258). E. Posterior body region of the male holotype (NIWA 139257). Scale bar: A $=65 \mu \mathrm{m}, \mathrm{B}-\mathrm{C}=15 \mu \mathrm{m}, \mathrm{D}-\mathrm{E}=25 \mu \mathrm{m}$. 


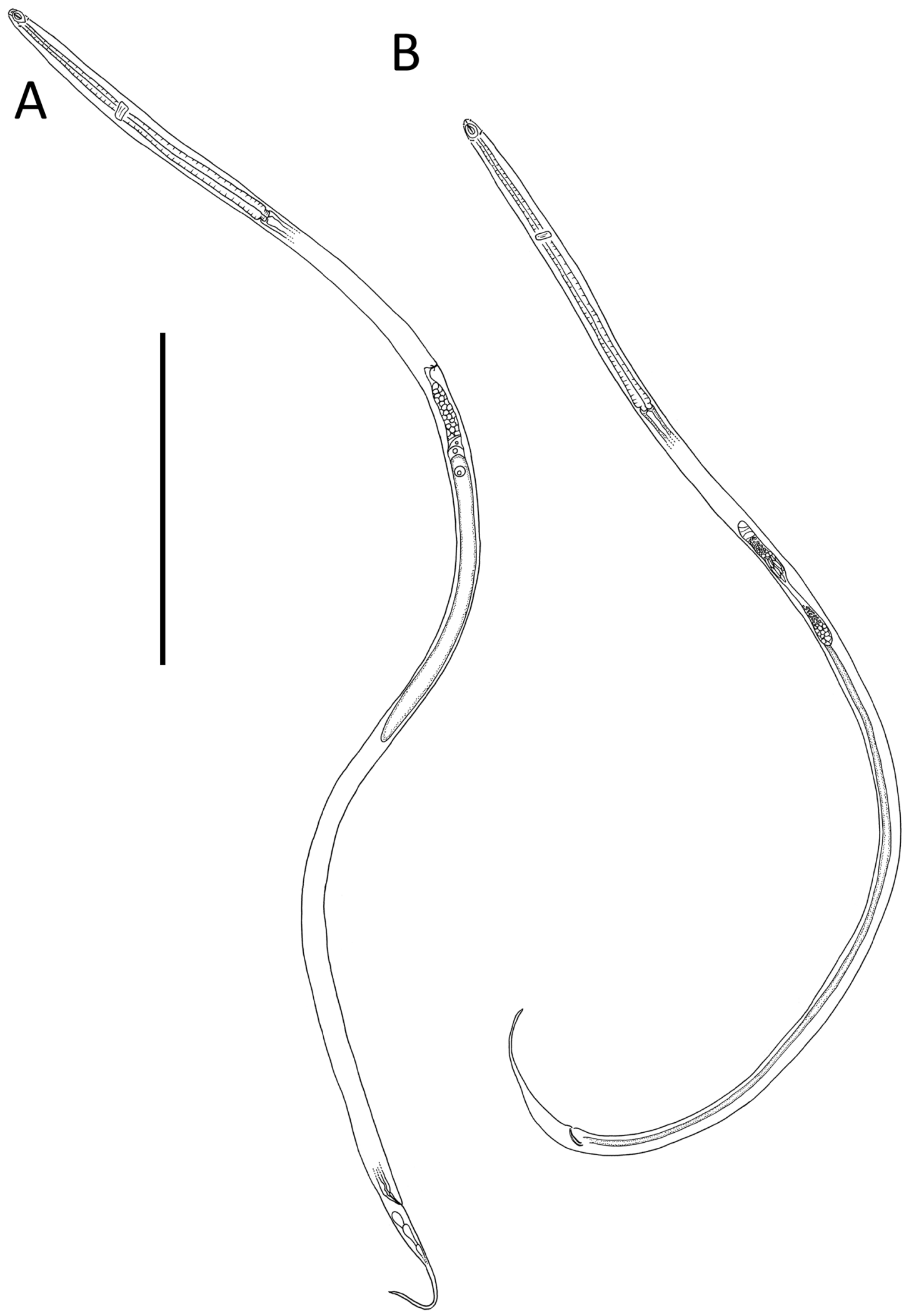

Fig. 2. Litinium gludi sp. nov. A. Entire female paratype (NIWA 139258). B. Entire male holotype (NIWA 139257). Scale bar $=200 \mu \mathrm{m}$. 

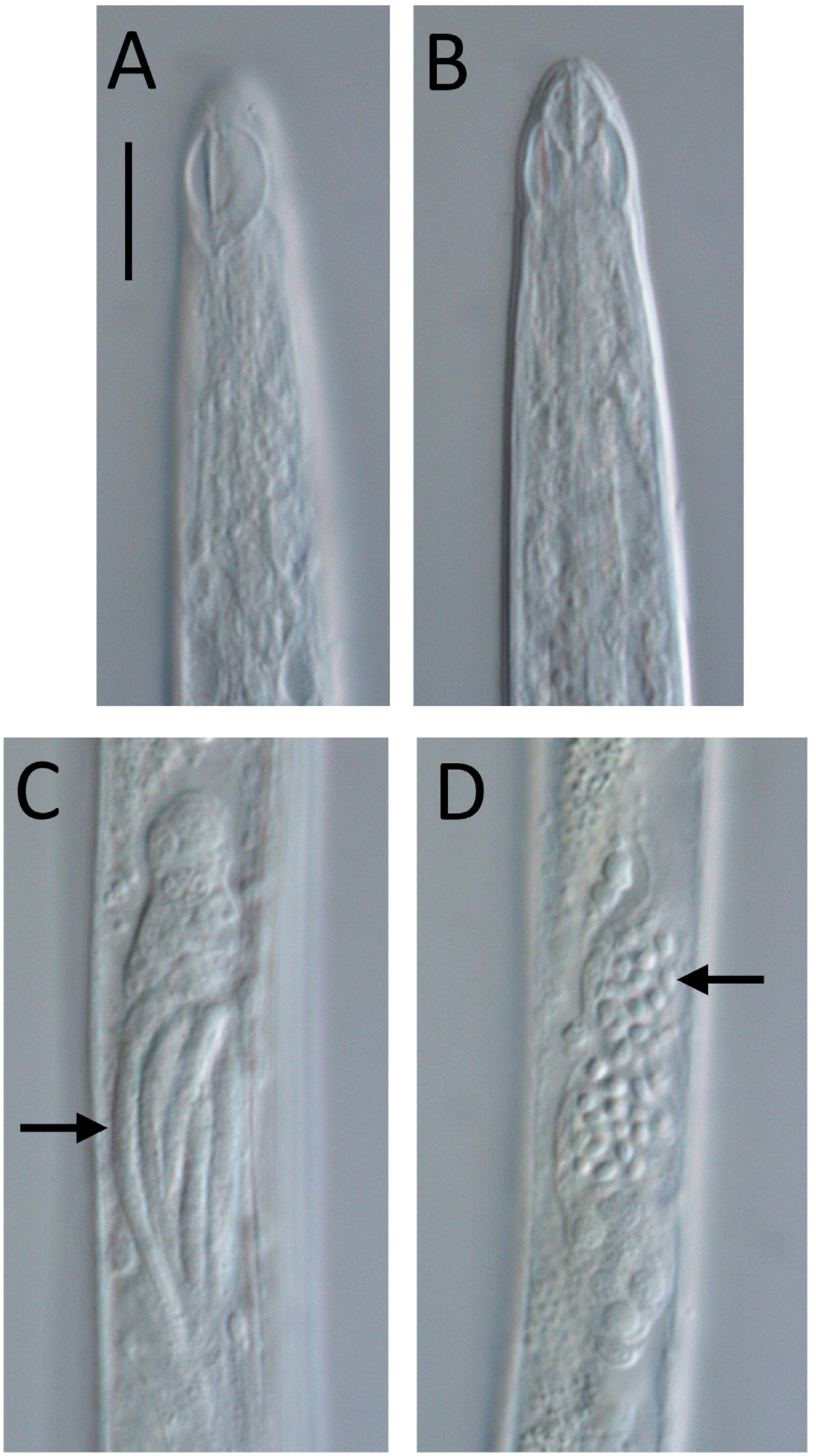

Fig. 3. Litinium gludi sp. nov., light micrographs of the male holotype (NIWA 139257). A. Surface view of cephalic region showing amphid and outer labial sensilla. B. Optical cross-section of cephalic region showing narrow buccal cavity and pharynx. C. Anterior testis showing elongated sperm cells (arrow). D. Posterior testis showing globular sperm cells (arrow). Scale bar $=10 \mu \mathrm{m}$. 
second precloacal papilla located 19-22 $\mu \mathrm{m}$ from posterior-most precloacal papilla. Ejaculatory glands not observed. Tail conico-cylindrical, with pointed tip, caudal capsule absent; three caudal glands present posterior to cloaca; spinneret not observed.

\section{Female}

Similar to males but without any somatic setae on tail. Reproductive system with single posterior genital branch and reflexed ovary. Oocyte up to $160 \times 10 \mu \mathrm{m}$. Vulva located far anteriorly at about $1 / 3$ of body length from anterior extremity. Vagina perpendicular to body surface; vaginal glands not observed.

\section{Molecular phylogenetic relationships}

Near full-length SSU (1516 bp) and D2-D3 of LSU sequences (756 bp) were obtained for Litinium gludi sp. nov. The Oxystominidae did not form a monophyletic clade in the consensus SSU tree due to the placement of Rhaptothyerus typicus Hope \& Murphy, 1969 and oncholaimoid sequences among the oxystominid sequences (Fig. 5). Neither the Halalaiminae (represented by Halalaimus and Oxystomina) nor the Oxystomininae (all other oxystominid genera) were recovered as monophyletic. Litinium

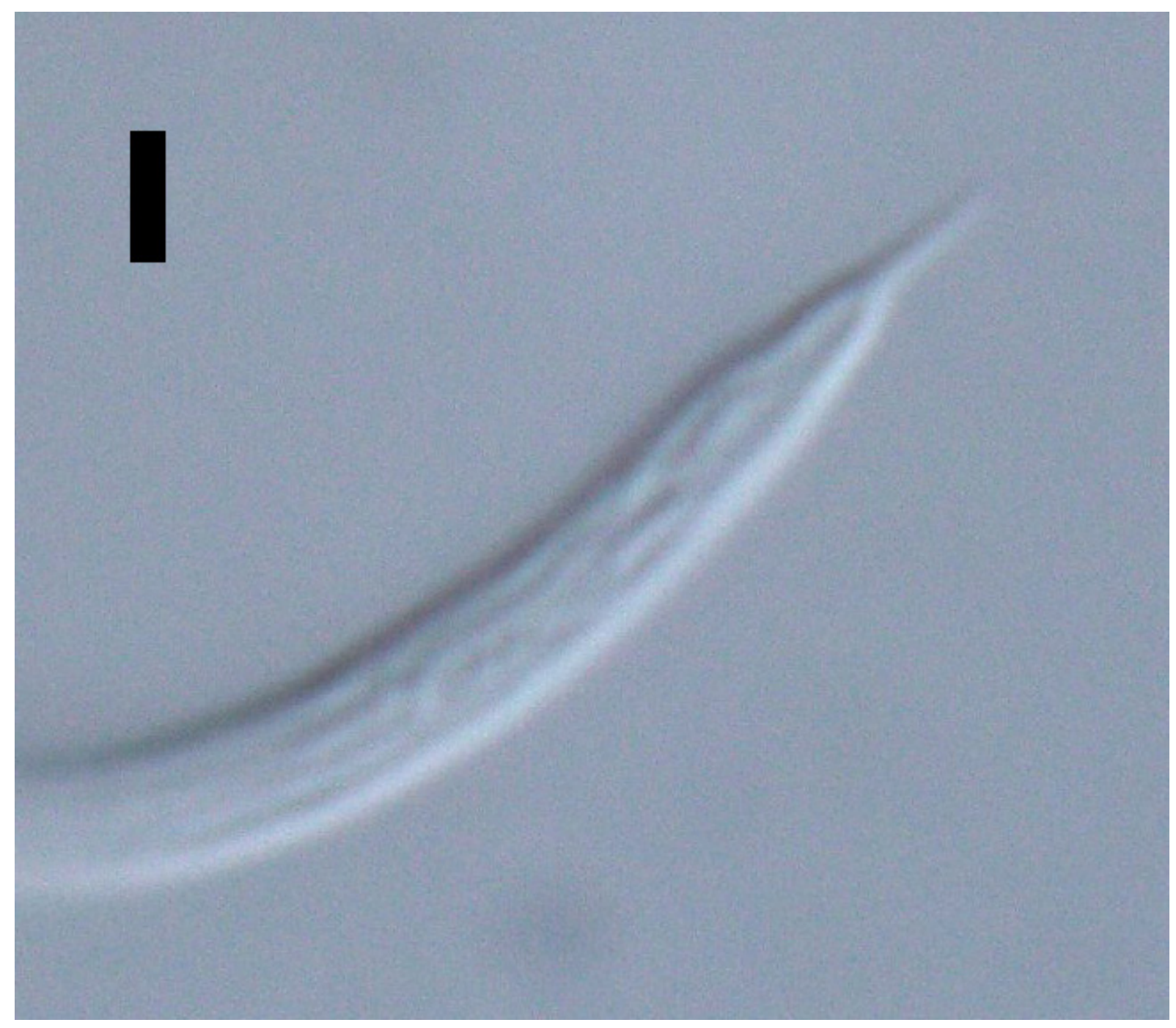

Fig. 4. Litinium gludi sp. nov., light micrograph of tail tip of the male holotype (NIWA 139257), showing absence of caudal capsule and spinneret. Scale bar $=2 \mu \mathrm{m}$. 


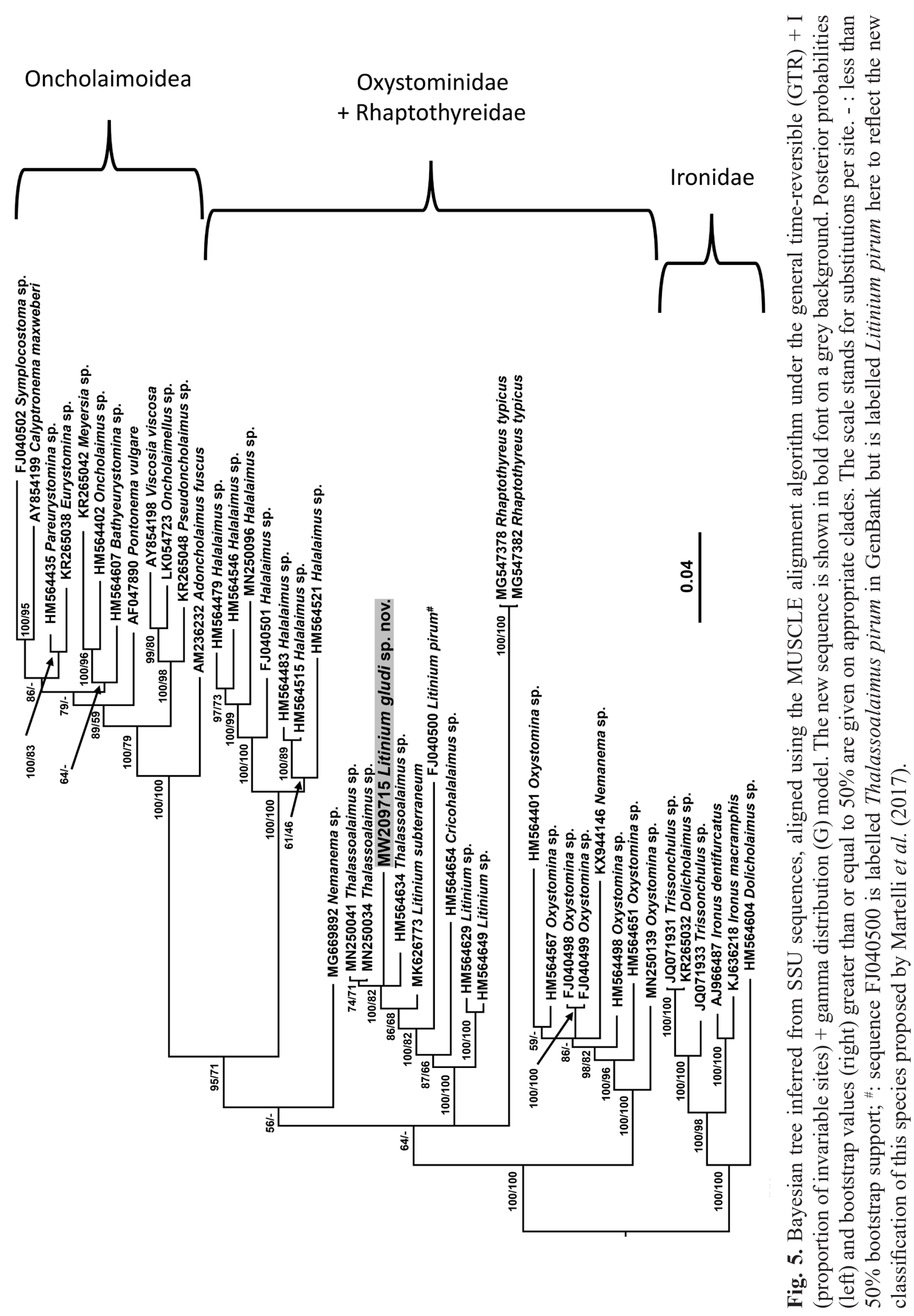




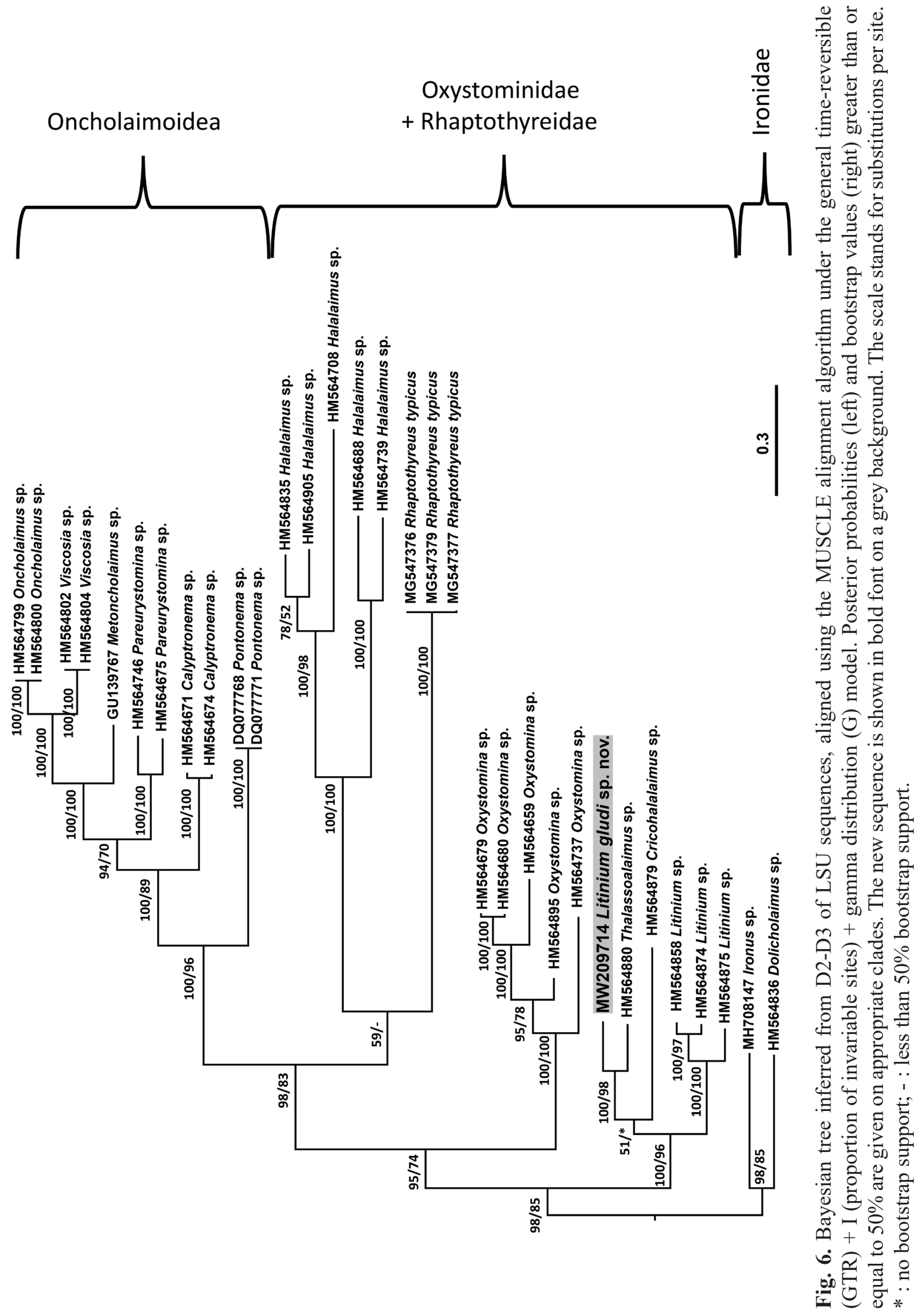


gludi sp. nov. was placed in a well-supported clade $(100 \%$ posterior probability and $82 \%$ bootstrap support) with sequences of Thalassoalaimus. The similarity between SSU sequences of Litinium gludi sp. nov. and Thalassoalaimus sp. was 94-95\% with a difference of 69 in 1508 nucleotides with 4 gaps (MN250034), 83 in 1504 nucleotides with 1 gap (HM564634) and 43 in 798 nucleotides with 1 gap (MN250041). The Litinium gludi sp. nov. + Thalassoalaimus clade was part of a wider, strongly supported oxystominid clade including all sequences of Litinium and Cricohalalaimus (100\% posterior probability and bootstrap support), although neither Litinium nor Thalassoalaimus were monophyletic. The similarity between SSU sequences of Litinium gludi sp. nov. and Litinium sp. was $87-94 \%$ with a difference of 84 in 1513 nucleotides with 5 gaps (FJ040500), 116 in 1516 nucleotides with 3 gaps (HM564629), 113 in 1514 nucleotides with 2 gaps (HM564649), and 46 in 786 nucleotides with 1 gap (MK626773). Sequences of Halalaimus formed a strongly supported (100\% posterior probability and bootstrap support) monophyletic sister group to the Oncholaimoidea Filipjev, 1916, the latter also forming a strongly supported monophyletic group (100\% posterior probability and bootstrap support). The sequences of Oxystomina formed a strongly supported group (100\% posterior probability and bootstrap support), however this genus was not monophyletic due to the inclusion of a sequence of Nemanema Cobb, 1920 in the clade. The placement of another sequence of Nemanema as a sister group to the Halalaimus + Oncholaimoidea clade was poorly supported ( $56 \%$ posterior probability and $<50 \%$ bootstrap support).

The topology of the D2-D3 of LSU consensus tree was similar to that of the SSU tree, with the Oxystominidae again not recovered as monophyletic (Fig. 6). Sequences of Halalaimus and Oxystomina each formed strongly supported monophyletic clades (100\% posterior probability and bootstrap support). As in the SSU tree, Litinium, Cricohalalaimus, and Thalassohalaimus formed a strongly supported clade (100\% posterior probability and bootstrap support), with Litinium gludi sp. nov. most closely related to Thalassoalaimus (100\% posterior probability and $98 \%$ bootstrap support). The similarity between LSU sequences of Litinium gludi sp. nov. and Thalassoalaimus sp. was $92 \%$ with a difference of 118 in 664 nucleotides with 7 gaps (HM564880); the similarity between LSU sequences of Litinium gludi sp. nov. and Litinium sp. was $71-72 \%$ with a difference of 188 in 671 nucleotides with 13 gaps (HM564858), 184 in 671 nucleotides with 12 gaps (HM564874) and 183 in 671 nucleotides with 13 gaps (HM564875).

\section{Discussion}

The topologies of our SSU and D2-D3 of LSU trees are very similar to the phylogeny of Bik et al. (2010a), which recovered four sub-clades: Oncholaimoidea, Thalassoalaimus + Cricohalalaimus + Litinium, Oxystomina, and Halalaimus. Bik et al. (2010a) noted that Halalaimus was consistently recovered as a long-branch clade, which may have a destabilizing effect on the internal tree topology. The inclusion of Rhaptothyreus typicus in the present study, which was also recovered as a long-branch clade, may have had a similar destabilizing effect, and the placement of this taxon in relation to the Oxystominidae as well as wider Enoplida remains uncertain (Leduc et al. 2018). Molecular phylogenetic analyses have not yet provided support for the monophyly of the Oxystomininae or Halalaiminae (Bik et al. 2010a; present study).

The morphology of Litinium gludi sp. nov. is consistent with other species of Litinium due to the shape of the amphids, the posterior position of the cephalic setae and the lack of a caudal capsule. However, both SSU and LSU trees indicate that the new genus is most closely related to Thalassoalaimus. The latter genus is similar to Litinium in the structure and position of cephalic sensilla, but differs from Litinium in having a caudal capsule. It should be noted that most of the sequences of Thalassoalaimus in GenBank were not identified to the species level, and that given the recent changes in the definitions of Litinium and Thalassoalaimus (Tchesunov et al. 2014; Martelli et al. 2017), some or possibly all of the sequences of Thalassoalaimus from GenBank included in our phylogenetic analyses may in 
fact belong to Litinium or vice versa. For example, the SSU sequence of Thalssoalaimus pirum, the only sequence of Thalassoalaimus identified to species level in GenBank, has since been transferred to Litinium by Martelli et al. (2017) (see Fig. 4). This uncertainty puts into question the apparent close relationship between the new species and Thalassoalaimus in molecular analyses. Therefore, given the current morphological definitions of Litinium and Thalassoalaimus, we choose to place the new species within Litinium, despite the apparently contradictory findings of molecular analyses.

Our phylogenetic analyses provide strong support for the placement of the new genus within a clade containing both Thalassoalaimus and Litinum, and within the Oxystomininae. Interestingly, the placement of Cricohalalaimus together with Thalassoalaimus and Litinium indicates that this genus, which is characterized by conflicting features used to define the Halalaiminae (elongated amphideal aperture) and Oxystomininae (female with single posterior ovary), should be placed within the Oxystomininae and not in the Halalaiminae as is currently the case (Smol et al. 2014). An analogous change to the classification of the Rhabdocoma Cobb, 1920 (Enoplida, Trefusiidae Gerlach, 1966 (De Ley \& Blaxter 2004)) was suggested by Shi \& Xu (2017), who found that SSU phylogenetic relationships supported the classification of this genus with the Halononchinae Wieser \& Hopper, 1967, a classification consistent with variation in the structure of the female reproductive system, and not in the Trefusinae Gerlach, 1966, as previously suggested based on buccal morphology. Similarly, in the case of Cricohalalaimus, it appears that the shape of the amphideal aperture is not as informative as the structure of the female reproductive system for subfamily-level classification, and we therefore propose that Cricohalalaimus be moved to the Oxystomininae.

\section{Acknowledgments}

We thank the co-voyage leaders Ronnie N. Glud and Ashley A. Rowden and science party of voyage TAN1711, and the officers and crew of $R V$ Tangaroa for their contribution to sample collection. The voyage was funded by European Research Council Advanced Grant (ERC adG 2014 grant agreement number 669947) as part of the HADES-ERC trench project, with additional support from various national research programmes. Funding for DL's participation in the voyage, and for the taxonomic analyses, was provided by NIWA's Coasts and Oceans Centre Research Programme 'Marine Biological Resources'. ZZ was supported by core funding for Crown Research Institutes from the Ministry of Business, Innovation and Employment's Science and Innovation Group. We are grateful to Megan Carter (NIWA) for processing the meiofauna samples and Duckchul Park (Landcare Research) for obtaining the molecular sequences. We thank two anonymous reviewers for providing constructive criticisms on the manuscript.

\section{References}

Allgén C.A. 1933. Freilebende Nematoden aus dem Trondhjemsfjord. Capita Zoologica 4: 1-162.

Bik H.M., Lambshead P.J.D., Thomas W.K. \& Hunt D.H. 2010a. Moving towards a complete molecular framework of the Nematoda: a focus on the Enoplida and early branching clades. BMC Evolutionary Biology 10: 353. https://doi.org/10.1186/1471-2148-10-353

Bik H.M., Thomas W.K., Hunt D.H. \& Lambshead P.J.D. 2010b. Low endemism, continued deepshallow interchanges, and evidence for cosmopolitan distributions in free-living nematodes (order Enoplida). BMC Evolutionary Biology 10: 389. https://doi.org/10.1186/1471-2148-10-389

De Ley P. \& Blaxter M.L. 2004. A new system for Nematoda: combining morphological characters with molecular trees, and translating clades into ranks and taxa. Nematology Monographs \& Perspectives 2: 633-653. 
Edgar R.C. 2004a. MUSCLE: multiple sequence alignment with high accuracy and high throughput. Nucleic Acids Research 32: 1792-1797. https://doi.org/10.1093/nar/gkh340

Edgar R.C. 2004b. MUSCLE: a multiple sequence alignment method with reduced time and space complexity. BMC Bioinformatics 5: 113. https://doi.org/10.1186/1471-2105-5-113

Gambi C., Vanreusel A. \& Danovaro R. 2003. Biodiversity of nematode assemblages from deepsea sediments of the Atacama Slope and Trench (South Pacific Ocean). Deep Sea Research Part I: Oceanographic Research Papers 50 (1): 103-117. https://doi.org/10.1016/S0967-0637(02)00143-7

Guindon S., Dufayard J.F., Lefort V., Anisimova M., Hordijk W. \& Gascuel O. 2010. New algorithms and methods to estimate Maximum-Likelihood phylogenies: Assessing the performance of PhyML 3.0. Systematic Biology 59: 307-321. https://doi.org/10.1093/sysbio/syq010

Holterman M., van der Wurff A., van den Elsen S., van Megen H., Bongers T., Holovachov O., Bakker J. \& Helder J. 2006. Phylum-wide analysis of SSU rDNA reveals deep phylogenetic relationships among nematodes and accelerated evolution toward crown clades. Molecular Biology and Evolution 23: 1792 1800. https://doi.org/10.1093/molbev/ms1044

Kearse M., Moir R., Wilson A., Stones-Havas S., Cheung M., Sturrock S., Buxton S., Cooper A., Markowitz S., Duran C., Thierer T., Ashton B., Meintjes P. \& Drummond A. 2012. Geneious basic: an integrated and extendable desktop software platform for the organization and analysis of sequence data. Bioinformatics 28: 1647-1649. https://doi.org/10.1093/bioinformatics/bts199

Leduc D. 2015. One new genus and five new nematode species (Monhysterida, Xyalidae) from Tonga and Kermadec Trenches, Southwest Pacific. Zootaxa 3964: 501-525.

https://doi.org/10.11646/zootaxa.3964.5.1

Leduc D. 2016. One new genus and three new species of deep-sea nematodes (nematoda: Microlaimidae) from the Southwest Pacific Ocean and Ross Sea. Zootaxa 4079: 255-271. https://doi.org/10.11646/zootaxa.4079.2.7

Leduc D., Zhao Z.Q., Verdon V. \& Xu Y. 2018. Phylogenetic position of the enigmatic deep-sea nematode order Rhaptothyreida: A molecular analysis. Molecular Phylogenetics and Evolution 122: 29-36. https://doi.org/10.1016/j.ympev.2018.01.018

Lorenzen S. 1981. Entwurf eines phylogenetischen Systems der freilebenden Nematoden. Veröffentlichungen des Instituts fur Meeresforschung in Bremerhaven 7: 1-472.

Martelli A., Lo Russo V., Villares G. \& Pastor de Ward C.T. 2017. Two new species of free-living marine nematodes of the family Oxystominidae Chitwood, 1935 (Enoplida) with a review of the genus Thalassoalaimus de Man, 1893 from the Argentine coast. Zootaxa 4250: 347-357. https://doi.org/10.11646/zootaxa.4250.4.5

Miljutin D.M., Gad G., Miljutina M.M., Mokievsky V.O., Fonseca-Genevois V. \& Esteves A.M. 2010. The state of knowledge on deep-sea nematode taxonomy: how many valid species are known down there? Marine Biodiversity 40: 143-159. https://doi.org/10.1007/s12526-010-0041-4

Nunn G.B. 1992. Nematode Molecular Evolution. PhD Thesis, University of Nottingham, UK.

Nylander J.A.A. 2004. MrModeltest. Ver. 2. Program distributed by the author. Evolutionary Biology Centre, Uppsala University. Available from https://github.com/nylander/MrModeltest2 [accessed 8 Apr. 2021].

Rambaut A. \& Drummond A.J. 2007. Tracer. Ver. 1.4. Available from http://beast.community/tracer [accessed 8 Apr. 2021]. 
Shi B. \& Xu K. 2017. Morphological and molecular characterizations of Africanema multipapillatum sp. nov. (Nematoda, Enoplida) in intertidal sediment from the East China Sea. Marine Biodiversity 48: 281-288. https://doi.org/10.1007/s12526-017-0690-7

Somerfield P.J. \& Warwick R.M. 1996. Meiofauna in Marine Pollution Monitoring Programmes: a Laboratory Manual. Lowestoft, Ministry of Agriculture, Fisheries and Food.

Smol N., Muthumbi A. \& Sharma J. 2014. Order Enoplida. In: Schmidt-Rhaesa A. (ed.) Handbook of Zoology: Gastrotricha, Cycloneuralia and Gnathifera. Volume 2: Nematoda: 193-249. De Gruyter, Berlin.

Swofford D.L. 2002. PAUP*. Phylogenetic Analysis Using Parsimony (and Other Methods). Ver. 4. Sinauer Associates, Sunderland.

Tchesunov A.V., Thanh N.V. \& Tu N.D. 2014. A review of the genus Litinium Cobb, 1920 (Nematoda: Enoplida: Oxystominidae) with descriptions of four new species from two contrasting habitats. Zootaxa 3872: 57-76. https://doi.org/10.11646/zootaxa.3872.1.5

Zheng J.W., Subbotin S.A., He S.S., Gu J.F. \& Moens M. 2002. Molecular characterisation of some Asian isolates of Bursaphelenchus xylophilus and B. mucronatus using PCR RFLPs and sequences of ribosomal DNA. Russian Journal of Nematology 11: 17-22.

Manuscript received: 29 November 2020

Manuscript accepted: 9 February 2021

Published on: 7 May 2021

Topic editor: Rudy Jocqué

Desk editor: Natacha Beau

Printed versions of all papers are also deposited in the libraries of the institutes that are members of the EJT consortium: Muséum national d'histoire naturelle, Paris, France; Meise Botanic Garden, Belgium; Royal Museum for Central Africa, Tervuren, Belgium; Royal Belgian Institute of Natural Sciences, Brussels, Belgium; Natural History Museum of Denmark, Copenhagen, Denmark; Naturalis Biodiversity Center, Leiden, the Netherlands; Museo Nacional de Ciencias Naturales-CSIC, Madrid, Spain; Real Jardín Botánico de Madrid CSIC, Spain; Zoological Research Museum Alexander Koenig, Bonn, Germany; National Museum, Prague, Czech Republic. 